University of Nebraska - Lincoln

DigitalCommons@University of Nebraska - Lincoln

Faculty Publications in Educational

Administration

Educational Administration, Department of

2020

Exploring cultural logic in becoming teacher: a collaborative autoethnography on transnational teaching and learning

Taeyeon Kim

Heather L. Reichmuth

Follow this and additional works at: https://digitalcommons.unl.edu/cehsedadfacpub

Part of the Bilingual, Multilingual, and Multicultural Education Commons, and the Educational

Administration and Supervision Commons

This Article is brought to you for free and open access by the Educational Administration, Department of at DigitalCommons@University of Nebraska - Lincoln. It has been accepted for inclusion in Faculty Publications in Educational Administration by an authorized administrator of DigitalCommons@University of Nebraska - Lincoln. 


\title{
Exploring cultural logic in becoming teacher: a collaborative autoethnography on transnational teaching and learning
}

\author{
Taeyeon Kim ${ }^{1}$ and Heather L. Reichmuth ${ }^{2}$ \\ 1 Department of Educational Administration, University of Nebraska-Lincoln, \\ Lincoln, NE, USA \\ 2 Department of Teacher Education, Michigan State University, East Lansing, MI, \\ USA \\ Correspondence - Taeyeon Kim, Department of Educational Administration, University of \\ Nebraska-Lincoln, Lincoln, NE, USA; tkim@unl.edu \\ ORCID Taeyeon Kim http://orcid.org/0000-0002-2020-9851
}

\begin{abstract}
Departing from the view that learning is a linear progression, we argue that through the lens of cultural historical activity theory (CHAT) and cultural logic, teacher learning research can be advanced. Applying these two constructs to a collaborative autoethnography of two emerging scholars' transnational teaching and learning experiences in the US and South Korea we argue that implicit and explicit norms in a culture influence the process of becoming teacher in the Korean context. Findings suggest that socio-cultural elements of implicit beliefs and norms outside of schools are linked to teacher learning inside schools, thereby suggesting that teacher learning at the microlevel needs to be understood alongside meso-level artefacts and macro-level factors in the complex process of becoming teacher. This study supports the view that becoming teacher is nonlinear and culturally situated.
\end{abstract}

Keywords: Teacher learning, CHAT, cultural logic, transnational teaching and learning, collaborative autoethnography, Korean education

Published in Professional Development in Education 2020

doi:10.1080/19415257.2020.1862278

Copyright (C) 2020 Informa UK Limited, Taylor \& Francis Group. Used by permission. Submitted 30 May 2020; accepted 23 November 2020; published 18 December 2020. 


\section{Introduction}

Challenging the notion of learning as linear and rationalized, research has argued that teacher learning should be understood as multifaceted; this learning should take into account teachers' individual background, disciplinary knowledge, the school environment, and culture (Lee and Schallert 2016, Strom et al. 2018, Johnson et al. 2019, Keay et al. 2019). Strom and Martin (2017) argue that understanding teacher identity and teacher learning should reflect contextual, co-constructive, and ongoing processes, suggesting the idea of "becoming" as opposed to traditional static notions of learning. This collaborative autoethnography aims to expand and refine how cultural contexts influence the meaning and process of becoming teacher in exploring the transnational experience of teaching and learning of our individual backgrounds in South Korea (from now on referred to as Korea) and the United States (US). Drawing on the cultural-historical activity theory (CHAT), we explore cultural logic - explicit and implicit assumptions and practices that exist within the broader social dimensions of a society (Tobin et al. 2009), which may explain our experience of becoming teacher in Korea as an ongoing process of teacher learning. ${ }^{1}$ Despite commonalities found in our cross-national contexts, this paper aims to explore the cultural logic that may have shaped our teacher learning experience in the Korean context. Our insights on cultural logic in this paper were gained by the contradictions we observed in two different educational systems and how we interpreted them.

We acknowledge the difficulties inherent in examining cultural assumptions in transnational experiences because such investigation requires close and careful understanding of concepts and practices embedded within each system (Paine and Ma 1993, Tobin et al. 2009). We write this collaborative autoethnography as transnational scholars currently working in US academia who previously worked as school teachers and learners in Korea. We found the assumptions and norms around teaching and learning we previously experienced within an education system were challenged by different structures and perspectives in the other system. Our collaborations to understand teacher learning in the Korean context expanded our individual understanding and created collective understanding to make sense of what we experienced with teacher learning. Using video-cued conversations, autobiographical 
essays, and essay-based discussions between 2018 and 2020, we generated qualitative data from our teaching and learning experiences in Korea and the US.

Research using comparative perspectives have explored country-level characteristics, such as economic rewards, social status, teacher policy, and credential systems, to understand variations between countries regarding the recruitment and development of teachers (see Akiba and LeTendre 2009, Akiba et al. 2007, Kim and Lee, 2020, Darling-Hammond et al. 2017; R Kim et al. 2011, Han 2018, Park and Byun 2015, Barber and Mourshed 2007). The findings of these studies suggest that structures and norms about the teaching profession constructed at the national-level shape teachers' perceptions and practices, in addition to their individual characteristics and experiences. In this line of literature, the teaching profession in Korea has been highlighted for its high social status (E Kim and Han 2002), access to qualified teachers (Akiba et al. 2007, Kang and Hong 2008, Luschei et al. 2013), high retention rate (Han 2018), active professional development (Kim and Lee, 2020), and equitable teacher distribution (Jeong and Luschei 2019). Beyond structural uniqueness, researchers have explored cultural and historical contexts that may explain teaching and learning in Korea as compared to other countries. Scholars pointed out that education has been utilized as an engine for increasing social mobility and success for individuals, which spearheaded its fast-developing economy after the Korean war (Sorensen 1994, Schwekendiek 2017). The Confucius tradition, "where 'learning' was about human development and social cultivation based upon Confucian classics" (Han and Makino 2013, p. 458), was found to be another popular explanation (see Kim et al. 2011, Bhang and Kwak 2019; Sum and Kwon 2020). For example, Kim et al. (2011) suggested that teachers have been respected in Korean society as they were expected to be "the most intelligent and best moral exemplars" in history (p. 52), particularly during Korea's Joseon Dynasty (1392-1897). These scholars viewed this historical context as paramount to shaping the current expectations for Korean teachers to be scholar-teachers possessing rigorous content knowledge (Leung 2001). Furthermore, studies have shown that the strong aspiration for academic achievement in Korean society produced the largest "shadow education" system in the world (Baker and LeTendre 2005, p. 57). In this respect, Korean schoolteachers are also supposed to focus on students' socioemotional development 
and caring connection with their students because there is an assumption that content knowledge could be gained through shadow education (see Ro 2019).

Building on existing studies, the current study explores the cultural logic of becoming teacher in the Korean context, which is grounded in our transnational teaching and learning experiences. We argue that the findings of this study should not be understood as "the Korean way" or "the American way" as a representative form but as one of multiple ways to understand the cultural logic found in our individual experiences and collaborative interpretations. We hope that this study broadens our understanding of becoming teacher by challenging Western notions of teaching and learning. The findings link socio-cultural elements of implicit beliefs and norms outside of schools to teacher learning inside schools, thereby suggesting that teacher learning at the micro-level needs to be understood alongside meso-level artefacts (e.g., policies) and macro-level factors (e.g., historical background) in the complex process of becoming teacher (Bronfenbrenner 1994).

\section{Invitation to our story: who we are}

During the time of this study, we were Ph.D. students in the college of education at a Midwestern university in the US. Through our teaching, learning, and research fieldwork in the US, we often found that dominant narratives within the scholarship of teacher education did not necessarily provide a space to understand our teacher learning in Korea because notions of teacher, teaching, and learning had been constructed differently in both spaces. These observations motivated us to collaborate on an autoethnography over the course of 2 years by individually and collectively reflecting on our transnational teaching and learning experiences.

Taeyeon: I remember the first day of my doctoral program's core course. I was the only international student listening to all the mysterious acronyms used in schools (e.g. local and state-level policies). I recall questioning several policies or systems that did not make sense to me (e.g. value-added assessments) by reflecting on my five and a half year's teaching experience as an elementary school teacher in Korea. I often found things that were considered as taken-for-granted in the Korean context of teacher education contradicted what I observed in the US 
context. During this time, I also experienced the discomfort of being the voice of the Korean educational system whenever I presented my research on Korean policy at international conferences. Even journal reviewers' comments on my English manuscripts on Korean education seemed to accept my arguments as "the Korean way" not as a perspective among multiple ways to interpret the phenomenon in Korea.

Heather: "What is the Korean perspective on this topic?" I felt myself perspire and possibly turn a little pink in the cheeks. The professor of one of my foundational teacher education courses and the class were silent, waiting for my response. I very rarely had a chance to share my 15 years' teaching experience (private institutes, high school, and university) in Korea during my classes, but now that I did, I felt uncomfortable. How could I package my experience, which I knew may be different from others in Korea, for a group who have not taught in or even been to Korea? I worried that I would misrepresent Korea with a brief response in class without being able to contextualize the Korean educational system. Additionally, I wondered if it was fair for me to be a Korean representative when I am a White American female and experienced teaching in Korea in different ways than my Korean colleagues.

Taeyeon and Heather: Living with such wandering thoughts in academia and our personal teaching histories, we wanted to share our stories and give voice to our experiences. Our personal conversations came together through a graduate student workshop arranged to guide students' preparation for an international conference as well as through sitting together in a comparative education course on teaching and learning, which motivated us to conduct the current study. We found collaborative autoethnography as both a method and methodology (Chang et al. 2016) that allowed us to share our stories by highlighting teaching and learning through the lens of cultural logic.

\section{Theoretical and analytical perspectives}

To understand teacher learning through our transnational experiences, we employed cultural logic as our analytic lens (Tobin et al. 2009) while 
drawing on CHAT to focus on culturally and institutionally created norms and actions found in our teaching and learning contexts (Penuel et al. 2016). We first discuss CHAT as a framework to situate this collaborative autoethnography as our learning experience across two cultures. We then introduce cultural logic as the analytic lens of this study, which we found useful to explain what we have learned about teacher learning through our embodied cross-cultural experience.

\section{Cultural-historical activity theory}

Researchers have applied CHAT in educational settings to showcase the cultural and social construction of human learning and development (i.e., Gutiérrez et al. 1999, Engeström et al. 2002). CHAT has its origins in Leont'ev's (1978) sociocultural learning theory of cultural mediation. Vygotsky argued that a stimulus and response are transcended by a mediated act (the well-known triangular-shaped model associated with Vygotsky) and culture plays a substantial role in this mediation. According to Vygotsky, artefacts such as books, desks, or videos are cultural products and tools which mediate an individual's learning. He explained that artefacts can modify human activity and can transform humans in the process. This means that as we use artefacts, they can alter the way we engage in an activity - for example, the use of computers for learning has dramatically changed how quickly we can access information.

Expanding on Vygotsky's work, Alekséi Leont'ev's (1978) work, considered the second generation of CHAT, introduced the concept of the division of labor between subjects as an addition to the analysis of activity; this addition brought learning to a collective level by examining an activity system(s). An activity system is defined as a system(s) of collaborative human practice (Engeström 1988). That is, as groups of people learn together, they engage in practices that lead them towards a partially shared goal. During this process, artefacts, rules, community, and divisions of labor are created to support the activity system(s). For example, the high school that Heather taught at while in Korea formed an activity system that had rules (i.e., class schedule, attending staff meetings), included the school community (i.e., homeroom teachers, language teachers, principal, students), division of labor (i.e., head teacher of the English department) and artefacts (i.e., lesson plans, policy documents). 
With the work of Vygotsky and Leont'ev as its foundation, Engeström (1987) laid the framework for the third generation of CHAT which allows us to observe how learning occurs within and between activity systems. The third-generation of CHAT has several guiding principles. These principles are: 1) activity systems are the main unit of analysis; 2) communities consist of multiple perspectives, views, interests, and traditions - thus are multivoiced; 3) historicity- activity systems morph and transform over time; 4) contradictions are created over time - contradictions produce disturbances and conflicts but also lead to innovation and change; and 5) expansive transformations are possible within activity systems.

In this paper, we note that the principle of contradictions is particularly useful to explore the cultural logic of our transnational experience as part of our learning across the activity systems. The fourth principle of contradictions explains how we made sense of our teaching and learning experiences through conflicting goals and tensions that existed within and between the two different cultures. According to CHAT, contradictions are inherent in any activity system; they are either ignored within an activity system or lead to change. At the basic level, whether these contradictions are ignored or challenged, depends on the culture. Then, if change does come forth, it can be either positive or negative depending on the actors, the system, and the culture. A number of studies have illuminated that the contradictions within activity systems can result in a transformation of teacher thoughts, behavior, and practices - including novice teachers' development of teaching strategies (e.g., Saka et al. 2009), impacts on professional development (e.g., Beatty and Feldman 2009), and teacher learning as a theory for praxis (e.g., Roth and Lee 2007). The use of CHAT allows for the exposure of contradictions which underscores the potential and limitations to change (Feldman and Weiss 2010).

In this study, which involves the transnational teaching and learning experiences of two emerging scholars, there are two activity systems that came into contact; the activity system of what teaching and learning is which we brought with us and learned from our upbringing (our histories) and the activity system with which we became involved when we went abroad and entered a new environment. Although there were many similarities to teaching and learning on the surface level, the implicit beliefs or unspoken rules and assumptions about teaching 
and learning in the new context created contradictions and tensions; in those spaces new growth and change emerged for both of us. In this paper, we strive to illuminate the spaces where growth and change happened by exploring the cultural logic we encountered in our experience of becoming teachers.

\section{Cultural logic}

Culture is a human entity that develops and changes over time through negotiations between multiple actors and institutions (Florio-Ruane 2001). We understand culture to involve meaning-making through symbols, gestures, collective narratives, and group memory (Hoerder 2013). It is found in the unspoken assumptions and norms held by community members and educators which are reified in schools (Bruner 1996, Anderson-Levitt 2002, 2012, Tobin et al. 2009). Culture has been the unit of analysis in a number of comparative research studies. For example, Anderson- Levitt (2002) described teaching cultures that exist on national and transnational levels, through her exploration of US and French first-grade classrooms. Tobin et al. (2009) illuminated the cultural norms and implicit notions about teaching shared among educators in China, Japan, and the US by exploring how teachers in each context understood best practices and learning in early childhood education. By exploring the failure of western pedagogies "transplanted" to Sub-Sahara Africa, Tabulawa (2013) argued that pedagogies are inherently valueladen and rooted in the sociocultural norms of a society. These findings imply that national-level culture can be seen as a paramount factor as to why, despite the similarities between teaching throughout the world today, differences exist.

Drawing on a longitudinal ethnography across three countries Tobin et al. (2009) presented the concept of cultural logic which refers to the "beliefs, goals, and concerns about education characteristic to a culture" (pp. 9-10) which are reified in the "explicit" and "implicit" beliefs present in a society. While explicit beliefs as marked beliefs can be exemplified within the written curriculum or policy documents in schools, implicit beliefs as unmarked beliefs are invisible, and take the shape of common sense assumptions about pedagogy, learning, and teaching practice shared by members of a society (Tobin et al. 2009). Drawing on Tobin et al. (2009), we understand cultural logic to encompass implicit 
and explicit beliefs and assumptions found in the language, actions, and structures within societies. We also found that this cultural logic aligns with the idea of "rules" in each activity system and are part of the multivoicedness of activity systems, underscored in CHAT. Rules are created in order to add structure to an activity system, they are basic and may be spoken and unspoken. By applying the lens of cultural logic to analyze our experiences, the implicit and explicit beliefs and assumptions found in the language of schooling, actions taken by society members related to schooling, and within teacher learning are illuminated. While we analyzed data generated from our experiences in Korea and the US, our findings on cultural logic situated in the Korean context of teacher learning where we experienced an ongoing learning process of becoming teacher (Lee and Schallert 2016, Strom and Martin 2017, Keay et al. 2019). We also note that our experience acquired in one culture enabled us to make implicit assumptions in the other culture more explicit and visible. We were able to do so by offering a frame of reference as well as prompting questions to challenge taken-for-granted notions of teacher learning.

\section{Methodology}

\section{Collaborative autoethnography}

In order to understand and elicit our experiences of teaching and learning in Korea and the US, we used collaborative autoethnography as our methodological approach (Chang et al. 2016). Collaborative autoethnography comes out of the autoethnographic tradition (Ellis and Bochner 2000) in which the researcher's personal experiences are used as primary sources of data (Chang, 2013). While in an autoethnography an individual researcher's experiences are documented, in a collaborative autoethnography two or more researchers "pool their lived experiences on selected sociocultural phenomena and collaboratively analyze and interpret them for commonalities and differences" (Hernandez et al. 2017, p. 251). Previous studies connected with teacher development and learning have drawn on collaborative autoethnography in order to explore transnational experiences and teacher education (e.g. Vellanki and Prince 2018). Through sharing our stories and experiences 
through autobiographical methods, and by exploring our interpretations of events through questioning and probing, we were able to explore researcher subjectivity and gain a clearer sense of each of our individual experiences; this gave voice to our social and cultural concerns experienced in our current context - a counter-culture shock for Heather and a culture shock for Taeyeon, experiences which were validated through the collaboration.

\section{Data generation and analysis}

We conducted three phases of data generation and analysis between October 2018 and May 2020. In Phase 1, informed by Tobin et al.'s (2009) research method, video-cued ethnography, we used videos from Preschool in Three Cultures Revisited: China, Japan, and the United States to generate our conversational data. We viewed the videos together and paused them when one of us was stimulated by the video and an audiotaped conversation of our interpretations of the teachers' behaviors and interactions with students along with our own personal experiences related to the scene ensued. In Phase 2, we wrote autobiographical essays (seven pages each) about our learning experiences growing up in our respective countries and then teaching and learning experiences in Korea and the US. We then shared our autobiographical essays and responded to each other's autobiography through written comments and questions. The essays were returned again and then questions and comments were responded to through writing. This iterative sharing process occurred three times and the series of essay-cued discussions were recorded and transcribed. In Phase 3, we individually and collectively identified "themes" reflecting on our data (Sawyer and Liggett 2012). Our collaborative analysis in Phase 3 also simultaneously generated data and ongoing findings as the nature of collaborative autoethnography as a method.

We conducted recursive analysis by reading transcripts, reflecting on essays, and writing multiple drafts of themes. We first individually explored ideas and concepts to generate themes by reflecting on the collected data. We then brought together our individually identified concepts and discussed the themes that were present in both of our experiences. After each discussion on themes, we individually drafted an analytic essay using the themes and exchanged drafts. While reading the 
other's draft, we commented, expanded on, and pushed back on each other's experiences, which generated six versions of collective drafts on themes. Furthermore, multiple versions of collective writing on thematic drafts served as an analytic process for this study. Through the process, we found that our discussions and analyses had centered on making sense of teaching and learning in the Korean context through the contradictions found in our transnational experience. In the final stage of analysis, we focused on the cultural logic found in our understanding of the Korean context where we both navigated becoming teacher. We found that our analysis highlighted three themes: 1) teacher learning in school contexts; 2) structures and policies shaping teacher development; and 3) socio-historical understandings of learning and teacher.

\section{Becoming teachers in the Korean context}

Despite commonalities across both cultures, our analysis focused on the cultural logic behind teacher learning in the Korean context as compared to our experiences in the US. We begin our analysis by highlighting the contradictions we experienced across the two different education systems which led us to collaboratively reflect on community, rules, and objects (goals) in schools as part of our teaching in Korea (micro-level). Next, our analysis reveals systematic structures and policies as mediating artefacts (meso-level) that shaped and influenced our practices and development as teachers. Finally, our analysis highlights what it means to learn in the broader socio-cultural context of Korea (macro-level) in making sense of what we experienced as part of becoming teachers.

\section{Teacher learning in schools: micro-level}

\section{Community as an informal bonding mechanism}

Researchers have noted the importance of community in teacher learning as it can provide norms and social capital as well as create a collaborative learning culture in school settings (Hargreaves and Fullan 2012). What we found unique in our experience in Korea was that the notions and practices of community were broader than those professionally defined in research situated in western settings. In addition to professional 
activities that we both participated in as part of the school community (e.g., professional learning communities, department meetings, mentorships), Heather commented on the social events she participated in at every school that she taught in, an experience shared by Taeyeon. Heather recalled that at the high school she taught at, "all the teachers in the school would go hiking and at the end of the school year, we'd go out to eat, drink, and to a karaoke room." For Taeyeon, these rituals were commonplace in most Korean schools. Taeyeon and Heather observed similar community activities in the US such as teacher luncheons and agreed that those activities were meant for teacher bonding. However, Heather noted differences by saying,

In the US, these [luncheons] are typically hosted at the school unlike in Korea where they take place after school. Although they are not in our contract [in Korea] to attend, it is assumed you will attend. It's unspoken.

Taeyeon recalled attending those events which were never specified in the job description of teachers, yet teachers implicitly felt it was part of their job to attend. As government employees, public school teachers (like Taeyeon) have to transfer schools every four to six years within their district. Therefore, the informal and formal school events helped Taeyeon adjust to the new school environment and get to know her new colleagues. Taeyeon said,

The events in the beginning of the school year often aimed to welcome and support new teachers and experienced teachers that transferred from other schools. At the end of semester or school year events, teachers would spend time together to say good-bye and wish well the people who were leaving the school or retiring.

We thought that communal activities outside schools offered opportunities for teachers to know their colleagues as friends, mentors, and people - knowing about their personal experiences in addition to their professional interests and career development. These after school events that teachers were expected to attend but never forced to attend, were an "unspoken" norm. This seemed to suggest that Korean teachers value 
bonding with their colleagues as an important part of their work life, not only in their workplace but also as part of their long-term career and lifelong experience. In this way, community for Korean teachers could be understood as a space to gather and understand the multi-voicedness of individuals and groups.

\section{Reflection of our teaching: students and colleagues}

We both found a large part of our teaching experience was about learning to teach better in order to grow. We both felt that our pre-service trainings were not enough when we entered the classroom. In her essay, Taeyeon reflected,

Even though I did student teaching across my college years, being in the classroom with 28 energetic 11-year-old students without another adult was difficult. As a new teacher, I was confident in my content knowledge, but I had to figure out how to make my classroom filled with love and joy as well as engage students in learning. I learned a lot from my students .... They taught me how to praise and how to express feelings of love in different ways.

Looking back at her teaching experience in high school, Heather also said, "When I entered the high school classroom, I was not prepared for the management skills and other pedagogical skills needed to teach .... I worked hard at improving my management skills, relationships with students, and also how I taught." Sharing our struggles with "real-world" problems in our classrooms, we found that the community around us, including students and colleagues, were critical in our ongoing development.

We both agreed that responses from students were key to developing our teaching strategies and communication skills. Understanding and developing rapport with them was critical to making our lessons more meaningful. At the elementary school, Taeyeon would eat lunch with her students and play with them during recess. At her high school, Heather would be invited to join student-led clubs and events as part of the community where teachers and students got together. With these relationships, we both experienced our students, regardless of their age, 
expressing and sharing their feedback or impressions about our lessons, teaching style, and evaluation tools outside the classroom. These interactions with students helped us understand our students more holistically and reflect on what we had taught, which also led us to develop new ideas and strategies to be better teachers. We both felt that students as part of our community offered valuable voices for our teaching, including formal and informal feedback, which was important for us to continue to learn and grow as teachers.

We also found our colleagues were critical in motivating and facilitating our professional development. We both had multiple opportunities for professional development (PD) - school-based PD, the district and office of education PD, and self-directed training courses offered by various teacher-training institutions. We recalled that teachers in the same grade (Taeyeon) or in the same subject group (Heather) would share teaching resources that they developed. Teachers in our schools also developed lesson plans, curriculum, teaching materials, or exams (Heather) together during grade or subject group meetings. In addition, the communities of teachers we developed in schools and out of schools encouraged us to participate in multiple PD sessions which continued our collective learning. As Heather continuously developed her expertise in teaching English and became the head teacher (both at the high school and university level), she also had opportunities to give lectures and workshops at multiple universities and for the office of education at the municipal level to other local English teachers working in secondary and higher education.

Taeyeon recalled that each teacher in most schools in Korea had two to four "open lesson" sessions over the course of a school year which were not often found in local schools she visited in the US. In these "open lessons," teachers invite parents, administrators, and colleagues who would share ideas and teaching strategies. Taeyeon said,

As a novice teacher, even later in my teaching, observing how other teachers managed their classroom and interacted with their students during the lesson was very helpful. Of course, I was nervous when I invited other teachers to my lesson. So, it was exciting and stressful, like doing a conference presentation or a job talk here. 
After “Open Lesson Week," each group of teachers got together to discuss what they learned from each other and asked questions to understand the rationale behind the teachers' actions and lesson plan. In such a context, veteran teachers and administrators were willing to learn innovative ideas from novice teachers instead of viewing them as unseasoned and in need of support.

Interestingly, we found that we never discussed student scores as a reflection of our teaching in schools but were more concerned about our interactions with students and student engagement in our classroom. After watching the video about preschools in the U.S. focusing on standardized testing since the No Child Left Behind Act (NCLB), we thought about several reasons to explain why we did not talk about test scores as a critical reflection of our teaching. Heather reflected,

I think the emphasis may not be on the score because the students go to academic hagwons and tutors. In addition, we cannot say that, for example, Heather was the teacher that got them a top score- the students and their "moms" are also responsible for their studying- and a student learned over the years from multiple teachers/tutors so one teacher could not be responsible for the student's achievement gains.

Agreeing with Heather, Taeyeon added another explanation in the elementary school context. "For elementary school students, the government and schools have tried so hard to move away from a test-based curriculum. In recent years, standardized testing has been removed. Therefore the policy could not explicitly underscore testing as part of

teacher evaluations." Without student test scores being the standard of our teaching ability, we instead focused on student engagement, the utilization of innovative teaching strategies to motivate our students, and students' physical and emotional welfare.

\section{Structures shaping teacher development: meso-level}

We found that there are several policies and structures that shape the community and teachers' ongoing development in Korea, which were not found in our experience in the US. First, through our conversations, we noted that "what's regarded as a teachers' job" is different. We as 
teachers in Korea were able to attend some required PD during our working hours after our lessons. Like most schoolteachers in Korea, we usually taught 3-5 classes per day. We were supposed to use the rest of our working hours for individual planning time, teacher training, administrative work, or teacher meetings. Taeyeon never questioned whether or not teachers' ongoing development and planning for lessons should be counted as a part of teachers' working hours before she heard American teachers had difficulties finding time for planning and collaborative PD hours. The teachers in the Midwestern state where Taeyeon worked on research projects stated they would spend five to seven hours teaching and then spend additional hours grading and preparing before and after school and at home. Heather noted that her mom who had been an elementary school teacher in New York State spent her evenings and time on the weekend grading at home. During the vacation months, Korean teachers are paid even though they do not technically teach students in class because teachers are supposed to learn innovative strategies and plan for the next semester, which is considered a part of a "teachers' job". The message underlying this policy is the importance of teachers as learners.

In terms of what teachers need to learn, we also found that the Korean system considered the area of teacher development more broadly than in the US. Taeyeon recalled that the Korean government policy promotes more than 60 hours of in-service training for teachers yearly, and over 200 institutions including online programs subsidized by the government offer teacher PD (Kim and Lee, 2020). Mandated PD offered by the district are directly related to curriculum and instructional core courses, but elective programs teachers can take for credit include a variety of topics including foreign language skills, humanities-related topics, or learning technology skills. Taeyeon noted the assumption behind this might be explained by the fact that teachers need to be challenged by different perspectives and develop competencies to catch up with "the fast-changing world" where our students are currently living so that teachers can prepare their students better for the future.

We also found differences between Korea and the US in terms of who are considered experts in teaching. We noted that the Korean teacher policy enables and encourages teachers to be instructors of teacher training programs at the district or national level. Taeyeon recalled some of her colleagues served as instructors at the university while remaining 
in their job as classroom teachers. When she shared this experience in her doctoral course, one of her classmates who was a former teacher in America said, "That would not happen here. Teachers are too busy to grade and prepare their lessons." The professor of the class added, "It's uncommon to imagine classroom teachers being an instructor or university-level instructors in the US." When Heather and Taeyeon had a follow-up conversation after the class, Taeyeon also brought up the issue of teacher evaluations, saying, "I was surprised by the teacher evaluation system in the US, most times principals are the sole evaluators and teachers don't receive feedback from 'teachers' whom I would consider experts in teaching." The implicit message in the Korean teacher evaluation policy which requires teachers to evaluate their colleagues is that teachers are experts in teaching and administrators respect their judgement. In terms of teaching, we felt respected as professionals in schools through the visible policies as well as through the invisible norms. These structures appeared to keep us motivated to develop individually and collectively as "experts," a norm of the teaching profession.

\section{Learning culture and the image of teacher: macro-level}

Our discussions also included the broader narratives around learning and the image of teacher in Korean culture. Beyond acknowledging differences between two systems, our analysis also shows that we made efforts to make sense of the events, practices, policies, and assumptions behind our experience of becoming teacher and to explain what made the visible and invisible norms possible in the Korean context. This section explains how we explored the cultural logic that permeated the socio-historical context of Korea beyond school settings based on our experiences.

\section{Community practiced in learning}

The analysis highlighted the practice of community as one of the critical elements for understanding our experience of teacher development. In both of our experiences as learners in Korea, learning was an act of community. Heather commented that as a student of Korean and hanji, ${ }^{2}$ there was always a sense of community with the instructor and her classmates. In her essay, Heather recalled her outside of class activities when she took hanji: 
There was a small group of four of us that would stay late in the evening and the teacher would either prepare food for us or take us out to eat. It seemed that we were her small family and we would eat communally together. This eating together bonded us further in that we shared a meal, our stories, our time. Learning was not only about the progression of my talent or skill but also the relationship that I had with my teacher and peers.

Heather's essay reminded Taeyeon of her graduate school learning experience during her master's program in Korea. Taeyeon commented on Heather's essay.

I miss this sense of community! When I was a full-time master's student, my relationship with my former advisor and peers was like "family," having lunch together, asking and commenting on each other's research inquiry, and working on projects together. Throughout those moments, we got to know more about each other as a person as well as a scholar.

Growing up in this learning environment, Taeyeon was surprised by how graduate study at her doctoral institution was individualized. She felt many students or faculty members wanted to protect their own time to accomplish tasks that they planned, not wanting to be interrupted by having lunch with others or giving advice unless these events were planned. She found that students who are active enough to seek advice can receive it, but students who are passive or shy to ask advice would never have the same opportunity to be advised. However, these "quiet students" could be advised and helped in the communal practice within the academic learning environment in Korea.

In the American context, this sense of community seemed to be framed as mentoring, separate from teaching. We acknowledged variations across individuals in the two societies because some teachers and professors in our college were more willing to offer this family-like community for their students. Even in the Korean context, younger generations tended to protect their own time instead of spending time with their colleagues outside of required tasks. Taeyeon also added there has been criticism that these "community" activities could increase financial and mental burdens on teachers and students if they do not want to be 
a part of them. We acknowledged that the practice of community may have decreased more recently in Korea.

Regardless of the possible differences, the practice of community in the broader context of Korea explains the bonding mechanism, collaborative learning opportunities, and socialization of the school culture that occurred in the communities in schools, as part of our experience with becoming teacher. Moreover, "the progression of relationships" among teachers and students observed in learning seem to be associated with centering the responses from students and our colleagues in our reflection of teaching in schools. It was important for us as teachers to understand our students and colleagues more than school policies as we embodied such practice of community in our daily work in schools.

\section{"Korea is such a learning obsessed society"}

Our collective discussions indicated that "learning is a lifestyle trend" in Korea, which explains the explicit and implicit notions around our teacher learning experience. Talking about her yoga, hanji, and Korean classes, Heather said, "Korea is such a learning-obsessed society. Everyone was learning something after their work. To be part of those conversations (with her colleagues and friends), I felt like I had to learn something." Looking back at her own experience as a student and teacher, Taeyeon agreed, "Learning something is like a trend in Korea and this also impacted my social circles as well." Heather also pointed out the visibility of learning in the public sphere in her essay.

Libraries are packed with children, youth, and adults studying beside each other. Cafés are also filled with adult students studying beside people out for a coffee .... Studying in Korea is both an individual and group activity. Though you may never speak to those next to you, you are in a sense in a group activity as the people around you are also studying.

We discussed why this "learning-obsessed" culture happened in Korea. One possible explanation we discussed was the large private education market, such as having many hagwons which offer instruction on various subjects for people; From learning another language to learning how to cook. Taeyeon noted, 
Whatever you want to learn, you can find the subject at a hagwon around you easily. Even department stores and big grocery markets operate learning centers which offer 10-30 courses for young kids to adults at an affordable price. It's like, you go shopping at Macy's or Walmart on weekends, and while you're there you take yoga, painting, or a foreign language class. I can't imagine doing this in the US.

In our experience, we both acknowledged that the education market outside of the formal P-20 education systems in Korea are ubiquitous (Reichmuth, 2020). Private academies like hagwons are good at profiting from people's desire to learn regardless of their age.

Reflecting on the learning culture in Korea, we also uncovered a historical artefact related to this phenomenon. One day, Heather asked Taeyeon why so many Korean peoples' tombstones say "student" followed by their name. After researching the topic, we discovered that during the Joseon Dynasty, people who did not pass the civil service examination before passing away had "hak-saeng" (student) written before their name instead of their position. Taeyeon joked, saying "How funny! This Confucius country expected everyone to be students for life. Lifelong learning started 500 years ago in this country!" We laughed. Taeyeon felt this heritage permeated into Korea's contemporary learning culture. Under the norms of Confucian traditions, ideal human beings are those who continue to cultivate themselves, by seeking knowledge, embodying that acquired knowledge in everyday life, and by pursuing a morally desirable character and lifestyle (see Bhang and Kwak 2019). Therefore, everyone is considered a student (learner) by making endless efforts to be closer to an ideal person.

We interpreted that the historical Confucius values of self-cultivation had combined with contemporary Western ideas of life-long learning and the neoliberal marketization of education. Government-initiated policies have also promoted a learning society by supporting multiple learning centers in local communities (Han and Makino 2013). The Confucius value of human development as learning has been replaced by Western liberal arts subjects in contemporary education (Han and Makino 2013). This explains why teachers in Korea are expected to learn and develop and are not limited to content knowledge alone but expected to broaden their insights around human development, which will 
impact their teaching and students' learning. We also understood that the emergence of the private educational sector created popular discourses around lifelong learners and established accessible systems for learning (Han 2008). Thus, continuous learning and development for teachers in the Korean context can be understood in this unique ecology of a "learning obsessed society".

\section{The image of teachers}

We noted that labels and terms used for teachers reflect how a society views and identifies teachers. Taeyeon brought up differences found in the use of language for teachers in the two societies.

In Korea, when I was asked about my job, I used to say, "I am a schoolteacher (gyo-sa)." However, teachers or former teachers in the US say, "I taught" using the verb form of teach as opposed to the noun form, teacher. I was curious why in the US saying I taught has the same meaning as being a professional "teacher." In Korea, teachers, like other professionals, use the noun form of their title.

Heather responded that, in the US, to say, I teach or I taught implies the profession and therefore is assumed to be a job that is done by trained individuals. On the other hand, in Korea, based on Taeyeon's experience, there is a distinction between the kind of teacher someone is and the professional role of a teacher. Thus, it is safe to say that in Korea, teaching can be done by many, but schoolteachers have distinct titles making their professional role clear.

The image of gyo-sa used in professional contexts to refer to schoolteachers in Korea seemed to be connected to the social and economic status of teachers within the society. Taeyeon was sometimes upset when people viewed teaching as an easy job. However, oftentimes, the view of being a schoolteacher held by others usually came with admiration as well. She recalled her students' parents wanted their kids to become schoolteachers, one commented that "you must have been a top student in your school". Taeyeon had mixed feelings about how others commented on teaching: "yes this is a highly regarded job," but at the same time, "my salary is not good compared to other professionals or what I could earn in the private sector." 
We both agreed that this image of teacher is connected to the economic landscape of the country as well as the concept of school education within the society. Taeyeon remembered that $70 \%$ of her class peers at her university (focused solely on elementary preservice education) had already studied at other high-ranking universities. She recalled, that since the IMF economic crisis in the late 1990s, job conditions in the private sector had become less stable. Therefore, government jobs become more competitive because they were considered "life-long jobs" with attractive benefits. Public schoolteachers (Gyo-sa) are government employees so teachers can work until they are 62 and receive a decent retirement package.

While "gyo-sa" is a formal term to refer to schoolteachers in professional contexts, such as in official law and policy documents, there are other linguistic terms to refer to teachers in Korea, such as "seon-saeng" or "seu-seung". These terms are often used to call teachers or someone with respect. For example, students and parents call their teachers "seonsaeng-nim" ("nim" is an honorific term that follows a person's position or name). The literal meaning of "seon-saeng" or "seu-seung" indicates someone who lived/is born before another, implying those who can guide the lives of others. Our memories with Teachers (seu-seung)' Day in Korea shows how the society expresses appreciation for teachers' hard work. Heather recalled how she was surprised by her first Teachers Day, saying

There was a ceremony in the morning where all the students lined up across the courtyard and a student representative thanked us. The students all bowed to us and pinned corsages to our chests. Then at lunch, there was a fancy meal with expensive dishes prepared for the teachers. I had never seen teachers treated in this way.

Taeyeon recalled how her former students and their parents prepared a surprise for her, making her cry by singing the song, "Gratitude for Teachers" that starts with the lyrics, "teachers (seu-seung)' care/love is like the sky ... teachers (seu-seung) are parents in my heart." While Teachers' Day ceremonies and events have been reduced to avoid possible financial pressures on parents, Taeyeon said she still receives messages from her former students or parents who express their gratitude. 
Our conversations further linked the meaning of "seon-saeng" to the historical context of Korean society. After watching a documentary about a famous scholar of the Joseon Dynasty, Taeyeon said, "Only a few respected scholars during the Joseon Dynasty could have 'seon-saeng' in front of their name on their tombstone." Relatedly, she felt that being called "seon-saeng-nim" invoked feelings of respect and the term itself gave her authority. With such historical roots, becoming a teacher was more than a job; This included the norm that learning cannot be separated from our life as teachers - being responsible for our continuous learning to support and guide the life of our students. To hold our reputation of being teachers in Korea, our learning was not just about becoming experts in content knowledge or pedagogy, but also about a lifestyle in pursuit of self-cultivation and enriching our social relationships.

\section{Concluding remarks}

The findings of this study illuminate our experience of becoming teacher in the Korean context. Our transnational teaching and learning experience enabled us to explore the cultural logic found in schools, school policies, and in the broader context of Korean society, which influenced how and what we learned as teachers. As underscored in CHAT, the contradictions we experienced across two systems (US and Korea) allowed for the implicit norms and assumptions of the Korean system to become explicit (Tobin et al. 2009). In doing so, we explored the complex phenomena residing in socio-cultural contexts that may shape how teachers learn as an ongoing process (Keay et al. 2019; Strom and Martin 2019).

Our analysis suggests that the role of community can be further expanded to include bonding as an important part of the process of becoming teacher. Bonding opportunities that are informal can progress the relationship between teachers as well as teachers and students. These relationships in our individual experiences shaped our values and dispositions towards what our teaching and learning should look like because the relationships allowed us to reflect on our colleagues' and students' perspectives. The role of community within our learning context also supports existing findings that meaningful learning often starts with personally significant relationships beyond the professional or formal settings of learning (Kim 2020). Understanding multi-voices and knowing 
individual members of the community outside of formal, professional settings could be seen as an implicit rule for teachers as learners. The embodied practice of community in our experience served as a basis to deepen our informal and formal learning (Hager and Halliday 2007) about teaching and the teaching profession in the Korean context.

Relatedly, this study suggests that concepts of "learning" and "learners" in the context of teacher learning is cultural. Our transnational experience led us to discover that teachers are considered learners who should seek competency in content knowledge, pedagogy, and in multiple aspects of human relationships in Korea, which supports research findings on teacher identity and roles in Korea and East Asian countries (Leung 2001, Kim et al. 2011, Bhang and Kwak 2019, Ro 2019, Sum and Kwon 2020). Beyond their classroom teaching, individual and collaborative inquiry on lessons, self-development as teaching experts, and broadening perspectives on education were implicitly and explicitly understood as important elements of a teachers' job in Korea. Furthermore, with the historical notion of learning in Confucius traditions and the contemporary socio-cultural forces of life-long learning (Han 2008, Han and Makino 2013), teacher learning in the Korean context is not just for acquiring new knowledge to achieve certain standards and increase student achievement but also about reflecting on their own and others' practices to cultivate themselves as better teachers. While extensive research has framed teacher learning as a critical means for school reform and student achievement (Barber and Mourshed 2007, Darling- Hammond et al. 2017), our study suggests that teacher learning can be also viewed as an inherent process of becoming mature human beings as models, mentors, and individuals who can guide others' life experience.

Through cultural logic we found that the process of becoming teacher can be understood as part of a continuum of multi-dimensional learning (Lee and Schallert 2016; Strom and Martin 2017), suggesting that there may not be a perfect form of constructing identity and learning for teachers as life-long learners. This is connected with the meso-level policies that create career paths of the teaching profession and structures for daily routines and practices that support teacher learning in Korean schools. Our analysis shows that what enabled these structures are linked to the macro-level understanding of education - how the Korean society has historically and culturally viewed teaching, learning, 
and teachers. In this way, we revisited taken-for-granted norms and beliefs of the society to deepen the understanding of becoming teacher in the broader contexts.

We acknowledge that the findings of this study should be interpreted within the context of our subjective experiences as teachers and learners. While this collaborative autoethnography is one of the many possible explanations for our experience and interpretations, the current study expands our understanding of teacher learning. First, our analysis on transnational experience using the lens of cultural logic expands the application of CHAT to teacher learning by making implicit, unmarked beliefs and norms of each society more explicit through contradictions within and between our individual experiences across two systems. In addition, CHAT also supports the use of collaborative autoethnography as methodology as this study explores the process of our collaborative learning as transnational scholars across two activity systems. For comparative perspectives on teacher learning, the findings broaden our understanding of what, how, and why teachers learn, along with the meaning of teachers and the teaching profession that are culturally shaped within Korean society, beyond Western views on professional learning. In this way, our study offers implications for teacher education and practice, suggesting that individual experiences woven with socio-cultural contexts can be closely explored in the process of becoming teachers.

\section{Notes}

1. In this paper, we understand "teacher learning" and "becoming teacher" as interchangeable terms in our contexts. What we note as "teacher learning" should be interpreted as the complex, non-linear, and ongoing processes of becoming teacher.

2. Hanji is a Korean traditional paper making art form in which objects such as furniture can be made.

Acknowledgments This project was funded by the Department of Teacher Education in the College of Education at Michigan State University.

Disclosure No potential conflict of interest is reported. 


\section{References}

Akiba, M. and LeTendre, G., 2009. Improving teacher quality: the US teaching force in global context. New York, NY: Teachers College Press.

Akiba, M., LeTendre, G.K., and Scribner, J.P., 2007. Teacher quality, opportunity gap, and national achievement in 46 countries. Educational researcher, 36 (7), 369387. doi:10.3102/0013189X07308739.

Anderson-Levitt, K.M., 2002. Teaching culture as national and transnational: A response to Teachers' work. Educational researcher, 31 (3), 19-21. doi:10.3102/0013189X031003019.

Anderson-Levitt, K.M., 2012. Complicating the concept of culture. Comparative education, 48 (4), 441-454. doi:10.1080/03050068.2011.634285.

Baker, D. and LeTendre, G.K., 2005. National differences, global similarities: world culture and the future of schooling. Palo Alto, CA: Stanford University Press.

Barber, M. and Mourshed, M., 2007. How the world's best-performing school systems come out on top. London: McKinsey.

Beatty, I.D. and Feldman, A., 2009. Illuminating teacher change and professional development with CHAT. In: Proceedings of the NARST annual meeting, Garden Grove, CA, April, 17-19.

Bhang, J. and Kwak, D.J., 2019. The Public role of school teachers in Korea: for its conceptual reconstruction through its historical tracing. Educational Philosophy and Theory, 51 (9), 924-935. doi:10.1080/00131857.2018.1427573.

Bronfenbrenner, U., 1994. Ecological models of human development. In: International encyclopedia of education. 2nd ed. Vol. 3. pp. 1643-1647. Oxford: Elsevier. Reprinted in: Guavain, M. \& Cole, M. (Eds.). (1993). Readings on the development of children, (2nd ed.) (pp. 37-43). NY: Freeman.

Bruner, J.S., 1996. The culture of education. Cambridge, MA: Harvard University Press.

Chang, H. 2013. Individual and collaborative autoethnography as method. In: S.H. Jones, T.E. Adams, and C. Ellis, eds. Handbook of autoethnography. Thousand Oaks, California: Sage Publications, 107-122.

Chang, H., Ngunjiri, F.W., and Hernandez, K.-A.C., 2016. Collaborative Autoethnography. Abingdon, Oxon: Routledge.

Darling-Hammond, L., et al., 2017. Empowered educators: how high-performing systems shape teaching quality around the world. San Francisco, CA: John Wiley \& Sons.

Ellis, C. and Bochner, A., 2000. Autoethnography, personal narrative, reflexivity: researcher as subject. In: N. Denzin and Y. Lincoln, eds.. Handbook of qualitative research (pp. 733-768). 2nd ed. Thousand Oaks, California: Sage Publications.

Engeström, Y., 1987. Learning by expanding: An activity-theoretical approach to developmental research. Oy, Helsinki: Orienta-Konsultit

Engeström, Y., 1988. The cultural-historical theory of activity and the study of political repression. International Journal of Mental Health, 17 (4), 29-41. 
Engeström, Y., Engeström, R., and Suntio, A., 2002. From paralyzing myths to expansive action: building computer-supported knowledge work into the curriculum from below. In: G. Stahl, ed. Computer support for collaborative learning: foundations for a CSCL community. Hillsdale, NJ: Erlbaum, 211-224.

Feldman, A. and Weiss, T., 2010. Understanding change in teachers' ways of being through collaborative action research: A cultural-historical activity theory analysis. Educational action research, 18 (1), 29-55. doi:10.1080/09650790903484517.

Florio-Ruane, S., 2001. Teacher education and the cultural imagination. New York, NY: Routledge.

Gutiérrez, K.D., Baquedano-Lopez, P., and Tejada, C., 1999. Rethinking diversity: hybridity and hybrid language practices in the third space. Mind, culture, and activity, 6 (4), 286-303. doi:10.1080/10749039909524733.

Hager, P. and Halliday, J., 2007. Recovering informal learning: wisdom, judgement and community. Rotterdam, The Netherlands: Springer Science \& Business Media.

Han, S., 2008. The lifelong learning ecosystem in Korea: evolution of learning capitalism? International journal of lifelong education, 27 (5), 517-524. doi:10.1080/02601370802051637.

Han, S.H. and Makino, A., 2013. Learning cities in East Asia: japan, the Republic of Korea and China. International review of education, 59 (4), 443-468. doi:10.1007/s11159-013-9372-2.

Han, S.W., 2018. School-based teacher hiring and achievement inequality: A comparative perspective. International journal of educational development, 61, 82-91. doi:10.1016/j.ijedudev.2017.12.004

Hargreaves, A. and Fullan, M., 2012. Professional capital: transforming teaching in every school. New York, NY: Teachers College Press.

Hernandez, K.-A.C., Chang, H., and Ngunjiri, F.W., 2017. Collaborative autoethnography as multivocal, relational, and democratic research: opportunities, challenges, and aspirations. A/b:Auto/BiographyStudies, 32 (2), 251-254. doi:10.1080/08989575.2017.1288892.

Hoerder, D., 2013. Transculturalism. The Encyclopedia of Global Human Migration. doi:10.1002/9781444351071.wbeghm539.

Jeong, D.W. and Luschei, T., 2019. Teacher sorting within and across schools and nations: a comparative study of South Korea and the United States. Teachers College record, 121 (8), 1-40.

Johnson, C.S., et al., 2019. Learning about culture together: enhancing educators cultural competence through collaborative teacher study groups. Professional Development in Education, 1-14. doi:10.1080/19415257.2019.1696873.

Kang, N. and Hong, M., 2008. Achieving excellence in teacher workforce and equity in learning opportunities in South Korea. Educational Researcher, 37 (4), 200-207. doi:10.3102/0013189X08319571.

Keay, J.K., Carse, N., and Jess, M., 2019. Understanding teachers as complex professional learners. Professional Development in Education, 45 (1), 125-137. do i:10.1080/19415257.2018.1449004. 
Kim, E.G. and Han, Y.K., 2002. Attracting, developing and retaining effective teachers: background Report for Korea. Seoul: Korean Educational Development Institute.

Kim, R.Y., Ham, S.H., and Paine, L.W., 2011. Knowledge expectations in mathematics teacher preparation programs in South Korea and the United States: towards international dialogue. Journal of teacher education, 62 (1), 48-61. doi:10.1177/0022487110381999.

Kim, T. (2020) 'Becoming skillful leaders: American school principals' transformative learning', Educational Management Administration \& Leadership, 48 (2), 353-378. doi:10.1177/1741143218802596

Kim, T. and Lee, Y., 2020. Principal instructional leadership for teacher participation in professional development: evidence from Japan, Singapore, and South Korea. Asia Pacific Education Review, 21, 261-278. doi:10.1007/s12564-019-09616-x

Kim, T. and Lee, Y., 2020. Principal instructional leadership for teacher participation in professional development: evidence from Japan, Singapore, and South Korea. Asia Pacific Education Review, 21, 261-278.

Lee, S. and Schallert, D.L., 2016. Becoming a teacher: coordinating past, present, and future selves with perspectival understandings about teaching. Teaching and teacher education, 56, 72-83. doi:10.1016/j.tate.2016.02.004

Leont'ev, A.N., 1978. Activity, consciousness, and personality. Englewood Cliffs: Prentice Hall.

Leung, F.K., 2001. In search of an East Asian identity in mathematics education. Educational studies in mathematics, 47 (1), 35-51. doi:10.1023/A:1017936429620.

Luschei, T.F., Chudgar, A., and Rew, J.J., 2013. Exploring differences in the distribution of teacher qualifications across Mexico and South Korea: evidence from the teaching and learning international survey. Teachers college record, 115 (5), $1-38$.

Paine, L. and Ma, L., 1993. Teachers working together: A dialogue on organizational and cultural perspectives of Chinese teachers. International journal of educational research, 19 (8), 675-697. doi:10.1016/0883-0355(93)90009-9.

Park, H. and Byun, S.Y., 2015. Why some countries attract more high-ability young students to teaching: cross-national comparisons of students' expectation of becoming a teacher. Comparative education review, 59 (3), 523-549. doi:10.1086/681930.

Penuel, W.R., Cole, M., and O'Neill, D.K., 2016. Introduction to the Special Issue. Journal of the learning sciences, 25 (4), 487-496. doi:10.1080/10508406.2016.1 215753.

Reichmuth, H. L. 2020. Language investment of white native English-speaking wives in transnational marriages in Korea. I-LanD Journal, 1, 67-86. doi:10.26379/ IL2018001_12

Ro, J., 2019. Seeking the meaning of the job: Korean novice secondary teachers' professional identity. Asia pacific education review, 20 (1), 135-146. doi:10.1007/ s12564-018-9573-2. 
Roth, W.M. and Lee, Y.J., 2007. "Vygotsky's neglected legacy": culturalhistorical activity theory. Review of educational research, 77 (2), 186-232. doi:10.3102/0034654306298273.

Saka, Y., Southerland, S.A., and Brooks, J.S., 2009. Becoming a member of a school community while working toward science education reform: teacher induction from a cultural historical activity theory (CHAT) perspective. Science education, 93 (6), 996-1025. doi:10.1002/sce.20342.

Sawyer, R.D. and Liggett, T., 2012. Shifting positionalities: A critical discussion of a duoethnographic inquiry of a personal curriculum of post/colonialism. International Journal of Qualitative Methods, 11 (5), 628-651. doi:10.1177/1609 40691201100507.

Schwekendiek, D.J., 2017. South Korea: A socioeconomic overview from the past to present. New York, NY: Routledge.

Sorensen, C.W., 1994. Success and education in South Korea. Comparative education review, 38 (1), 10-35. doi:10.1086/447223.

Strom, K., Martin, A.D., and Villegas, A.M., 2018. Clinging to the edge of chaos: the emergence of practice in the first-year of teaching. Teachers college record, 120 (7), 1-32.

Strom, K.J. and Martin, A.D., 2017. Becoming-teacher: A rhizomatic look at first-year teaching. Rotterdam, The Netherlands: Springer.

Sum, E.S.W. and Kwon, O.N., 2020. Classroom talk and the legacy of Confucian culture in mathematics classroom. Teaching and Teacher Education, 88, 102964. doi:10.1016/j.tate.2019.102964

Tabulawa, R., 2013. Teaching and learning in context: why pedagogical reforms fail in Sub-Saharan Africa. Senegal: CODESRIA.

Tobin, J., Hsueh, Y., and Karasawa, M., 2009. Preschool in three cultures revisited: china, Japan, and the United States. Chicago, IL: University of Chicago Press.

Vellanki, V. and Prince, S.P., 2018. Where are the "People like me"?: A collaborative autoethnography of transnational lives and teacher education in the US. The Teacher Educator, 53 (3), 313-327. doi:10.1080/08878730.2018.1462873.

Vygotsky, L.S., 1987. Mind in society: the development of higher psychological processes. Cambridge, MA: Harvard University Press. 